\title{
A simple method of improving leverpress avoidance by rats
}

\author{
FREDERICK J. MANNING, MASON C. JACKSON, Jr., and JOHN H. McDONOUGH, Jr.* \\ Walter Reed Army Institu te of Research, Washington, D.C. 20012
}

\begin{abstract}
In three experiments, rats were trained to avoid electric shock in a free-operant leverpress procedure. After stable performance was obtained, sessions were suspended for periods of 1 to 4 weeks. In 24 of 28 Ss, shock rates were lower, some by as much as $75 \%$, when avoidance sessions were resumed. This improvement extended throughout the entire $60-100-$ min session, and occurred despite variations in apparatus, strain of rat, length or efficacy of prevacation training, lesions in the amygdala, and unshocked exposure to the apparatus during "vacation."
\end{abstract}

Reliable production of efficient leverpress shock avoidance by rats has long been a nettlesome problem. Bolles (1970) considers this an inevitable consequence of selecting for reinforcement a behavior which is not a "species-specific defense reaction." Nevertheless, a number of suggestions have been offered as partial remedies to the often noted propensities of rats for leverholding and/or pressing only in short postshock bursts. For example, Biederman, D'Amato, and Keller (1964) recommend locating visual stimuli on the wall of the chamber opposite that holding the lever. Giulian and Schmaltz (1973) opt for appetitive preconditioning, Forgione (1970), for disabling the lever during and shortly after shock, and Cahoon and Crosby (1969), for reducing the size of the chamber to dimensions just big enough to accommodate the $\mathrm{S}$.

We offer in this paper still another technique for improving leverpress avoidance performance by rats. Discovered quite by accident in the course of research on the effects of restricted amygdaloid lesions on shock avoidance, it is the ultimate in simplicity and ease of application, requiring no equipment or skills whatsoever. No guarantee is extended by the authors, but our inability to undermine the technique by a wide variety of systematic and unsystematic variations suggests it is extremely robust.

\section{EXPERIMENT I}

This experiment was designed to investigate the effects of amygdaloid lesions on the acquisition and retention of free-operant avoidance. Such lesions disrupt acquisition of both active and passive avoidance with discrete trials (Goddard, 1964). No such disruption was noted in the present experiment, but 12 of 14 rats, experimental and control alike, did show a remarkable

\footnotetext{
*Now at Department of Psychology, University of Utah. In conducting the research described in this report, the investigators adhered to the "Guide for Laboratory Animal Facilities and Care," as promulgated by the Committee on Revision of the Guide for Laboratory Animal Facilities and Care of the Institute of Laboratory Animal Resources, National Academy of Science-National Research Council.
}

improvement in shock avoidance over a 3-week "recuperation" from surgery.

\section{Method}

Subjects. Fourteen naive Long-Evans hooded rats were used. All were male, and weighed between 200 and $300 \mathrm{~g}$. Three rats had received bilateral lesions within the amygdaloid complex 3 weeks prior to the beginning of the experiment. Seven others underwent similar surgery in the course of the experiment. The remaining four underwent sham operations. All Ss were individually caged and had free access to food and water throughout the experiment.

Apparatus. Avoidance training and testing were conducted in a single plastic and stainless steel chamber $8 \times 9 \frac{1}{4} \times 8$ in., with a floor of 16 stainless steel bars. A single Lehigh Valley compound rodent lever was mounted in the lower-right corner of one of the two steel walls, protruding $1 \frac{1 / 4}{4}$ in. into the chamber. A single white jeweled light mounted $3 / 4$ in. above the lever operated briefly with each response, as did a single relay mounted on the ou tside of this wall 7 in. from the floor. A much larger box, $18 \mathrm{x}$ $18 \times 18$ in., constructed of plywood and lined with acoustic tile, enclosed the experimental chamber. The shock source was a BRS-Foringer constant-wattage shocker-scrambler (SGS-002) with the intensity setting at " 7 " ( $0.25 \mathrm{~W}$ in "stand-by mode") and the duration at $500 \mathrm{msec}$.

Procedure. Avoidance training consisted of 100-min free-operant avoidance sessions, with a shock-shock interval of $2 \mathrm{sec}$, and a response-shock interval of $20 \mathrm{sec}$. Each $\mathrm{S}$ was run 6 days per week on this schedule until his daily shock and response totals were judged stable over 10 sessions by two raters. Ss who had previously received lesions in the amygdala (Group AT) were then left undisturbed in their cages for 20 days. On Day 21, they were returned to the standard training regimen for a minimum of 5 days. All remaining rats were given either bilateral amygdaloid lesions (Group TA) or sham operations (Group SH) on the day following achievement of the required stability. They were returned to their home cages immediately following surgery and left undisturbed for 19 days, after which avoidance sessions were reinstated.

\section{Results}

No statistically reliable differences among the three groups could be discerned in either response rates or shock rates, either before or after their 20-day "vacation." The distinctions are therefore not maintained in the following analysis. Figure 1 shows the mean number of shocks and responses for all 14 rats in each of their final five sessions prior to vacation, and 


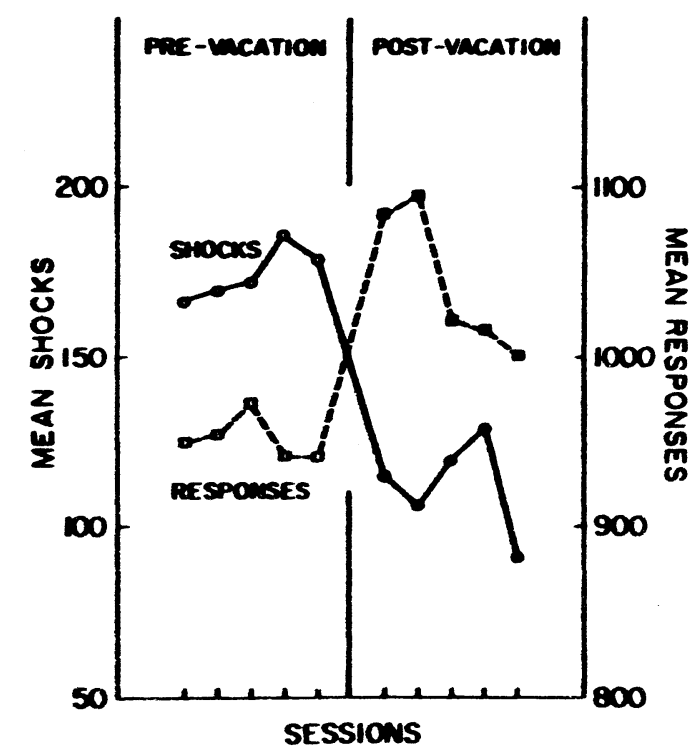

Fig. 1. Mean shocks and responses in each of the final five sessions prior to, and the first five sessions subsequent to, a 3-week "vacation." $(\mathrm{N}=14)$

their first five sessions after vacation. Response rates increased sharply in the five postvacation sessions, with an accompanying plunge in shock rates. Eleven of the 14 rats showed this elevation in response rate, and 12 of 14 showed a decrease in shock rate. Wilcoxon matched-pairs signed-ranks tests on the two 5-session blocks found both the increase in responses and the decrease in shocks significant at the .01 level $(\mathrm{T}=3)$. A Pearson correlation between change in shock rate and change in response rate was $-.59(\mathrm{p}<.02)$. That is, large decreases in shock rate were associated with large increases in response rate. However, regression analyses (linear, parabolic, exponential, power) revealed no significant relationships between either baseline measure and either vacation-induced change.

A finer-grained analysis was also attempted, by inspection of within-session changes in shock rate. We compared the mean number of shocks received in successive 10-min blocks for five sessions immediately prior to vacation to similar data from the five sessions after vacation. Both pre- and postvacation performances were characterized by highest shock rates in the first 10 min (warm-up decrement), but vacation did not improve performance by selectively affecting "warm-up decrement." Postvacation shock rates were lower over the entire session.

\section{EXPERIMENT II}

A 3-week hiatus from daily free-operant shock avoidance sessions clearly produced a sharp reduction in the shock rates of highly trained rats (presumably performing at asymptotic avoidance rates). Although these data are unequivocal, the purely fortuitous nature of this discovery, and the fact that a majority of the Ss had lesions in the amygdala, demanded a replication with normal Ss. Experiment II served this end, as well as extending the generality of the phenomenon to 15 - and 30-day vacations.

\section{Method}

Subjects and Apparatus. Eight naive male Long-Evans rats weighing $300-400 \mathrm{~g}$ were used. Avoidance training was conducted in two identical BRS-Foringer operant chambers. A single BRS rodent lever was mounted in the lower-right corner of one wall, protruding $1 \frac{1 / 4}{\mathrm{in}}$. into the chamber. Shocks were provided by BRS shockers (Model SG 1154) in conjunction with Model 1925 scramblers. Both shockers were set at the intensity rated " 3 " on the selectors $(2.0 \mathrm{~mA})$. Shock duration was $500 \mathrm{msec}$. White noise at $75 \mathrm{~dB}$ filled the chamber during avoidance sessions.

Procedure. Ss were randomly assigned to one of the two testing chambers and were run in the same box 5 days per week throughout the course of the experiment. Each rat was given a 1-h free-operant avoidance session 5 days per week. This shock-shock interval was $2.5 \mathrm{sec}$, and the response-shock interval was $20 \mathrm{sec}$. Each $\mathrm{S}$ was run on this schedule until variation in his responses and shocks over a 5 -session sequence was less than $\pm 5 \%$, with a 25 -session minimum. Upon achieving criterion, Ss were were assigned randomly to one of two groups and placed on vacation. One group ( 2 weeks) received 14 days vacation and the other group ( 4 weeks) received 30 days vacation. During the vacations, the Ss were left undisturbed in their home cages with free access to food and water. Starting on the 15th and 31st day, respectively, avoidance sessions were resumed. The Ss were run for 20 postvacation sessions.

\section{Results and Discussion}

Substantial inter-S variation precluded the use of group means, so data for each rat is presented in Table 1. Five session means for both shocks and responses are shown, starting with the final five prevacation sessions (baseline). The right-hand column is the difference between the baseline mean and the first block of five postvacation sessions. The upper half of this column reveals that all of the 2 -week rats and three of the four 4-week rats showed decreased shock rates after their vacation. The median decreases were 40 and 46 shocks, respectively $(17 \%$ and $16 \%)$. The two groups were not statistically different in this respect (Mann-Whitney $U=$ $6, p=.343)$. A Wilcoxon matched-pairs test pooling all eight Ss did show the decrease in shocks over vacation to be significant $(T=5, p<.05)$.

The bottom half of Table 1 contains a similar presentation of response rates. The right-hand column shows four decreases in response rate following vacation and four increases $(T=15, p=n . s$.$) , but the 2$-week and 4 -week groups did not differ $(U=4, p=.171)$. The "vacation effect" is thus best described as decreased shock rates, which may or may not be accompanied by increased overall response rates. The latter cases imply some change in response distribution, so interresponse time (IRT) distributions were examined for those rats for whom no change or even decreases in overall response rate accompanied decreased postvacation shock rates. In each case, 8 of our 102 -sec IRT intervals had increased frequencies following vacation, but the two extreme intervals showed large enough declines to offset 
Table 1

Mean Number of Shocks and Responses Per Session: Experiment II

\begin{tabular}{|c|c|c|c|c|c|c|c|}
\hline \multirow[b]{2}{*}{ Group } & \multirow[b]{2}{*}{ Ss } & \multicolumn{6}{|c|}{ Five-Session Blocks } \\
\hline & & Baseline & First & Second & Third & Fourth & Block 1-Baseline \\
\hline & & \multicolumn{6}{|c|}{ Shocks } \\
\hline \multirow{4}{*}{2 Week } & AV2 & 77 & 65 & 79 & 88 & 86 & -12 \\
\hline & AV4 & 296 & 243 & 253 & 321 & 312 & -53 \\
\hline & AV5 & 252 & 172 & 205 & 248 & 246 & -80 \\
\hline & AV7 & 299 & 272 & 207 & 216 & 165 & -27 \\
\hline \multirow{4}{*}{4 Week } & AV1 & 241 & 201 & 205 & 229 & 242 & -40 \\
\hline & AV3 & 79 & 28 & 22 & 20 & 23 & -51 \\
\hline & AV6 & 273 & 232 & 242 & 221 & 181 & -41 \\
\hline & AV8 & 336 & 384 & 378 & 359 & 354 & +48 \\
\hline & & \multicolumn{6}{|c|}{ Responses } \\
\hline \multirow{4}{*}{2 Week } & AV2 & 1135 & 1109 & 1250 & 1232 & 1166 & -26 \\
\hline & AV4 & 1304 & 1393 & 1336 & 1594 & 1614 & +89 \\
\hline & AV5 & 1226 & 1212 & 1210 & 1217 & 1248 & -14 \\
\hline & AV7 & 1409 & 1258 & 1115 & 1093 & 1217 & -151 \\
\hline \multirow{4}{*}{4 Week } & AV1 & 1349 & 1259 & 1479 & 1654 & 1785 & -90 \\
\hline & AV3 & 1428 & 1694 & 1438 & 1230 & 1269 & +266 \\
\hline & AV6 & 1813 & 1946 & 1670 & 1535 & 1796 & +133 \\
\hline & AV8 & 978 & 1037 & 1021 & 1200 & 1251 & +59 \\
\hline
\end{tabular}

these increases. It should be noted however, that the two intervals showing decreases in postvacation sessions reflect predominantly, if not entirely, shock-elicited bursts of leverpressing. The decrease in shock-elicited presses might be most parsimoniously attributed to the decrease in shock rate provided by increased responses in the middle 8 intervals. No indications of increased latencies (better "timing") were noted within these middle intervals.

Finally, it will be noted that four of the seven rats whose shock rates declined over vacation had essentially returned to their baseline shock rates by the end of 20 postvacation sessions. This return to baseline could not be related to any aspect of either baseline performance or vacation-induced change in performance. The following experiment includes an attempt to cope with this difficulty.

\section{EXPERIMENT III}

At the completion of the above experiments, the authors, still unable to accept the notion of improvements in asymptotic performance without practice, clung to the view that these rats had indeed forgotten something over their vacations, but that this "something" ordinarily disrupted rather than facilitated efficient avoidance. Silvestri, Rohrbaugh, and Riccio (1970) showed that retention of a locomotor avoidance response could be improved by brief exposure to the apparatus (without shock) during a 2-week retention interval. The experiment below incorporated such a procedure in an attempt to improve retention (and thereby presumably interfere with a vacation-induced decrease in shocks).

A second phase of this experiment investigated the effects of following one vacation with a second soon after the first. It was hoped this might prevent the "backsliding" noted in Experiment II.

\section{Method}

Subjects and Apparatus. Six male albino rats of the Wistar-derived Walter Reed colony, $300-400 \mathrm{~g}$, were used. Avoidance sessions were conducted in one of the two chambers used for Experiment II. Shock and schedule parameters were also identical to those of Experiment II.

Procedure. The initial phase of this experiment was identical to that of Experiment II, except that all rats received 15-day vacations. However, three of the six rats were given 30-min exposures to the experimental chamber (without houselights, white noise, or shocks) on Days 4, 8, and 12 of this vacation.

Phase II consisted of a second, shorter, vacation, of 7 days, beginning 16 sessions after the 15 -day vacation of Phase I. All six Ss were left undisturbed in the home cage for the full 7 days.

\section{Results and Discussion}

Two of the three rats left undisturbed for the 15-day vacation showed a decreased shock rate upon resumption of training $(-5 \%$ and $-19 \%)$. All three rats exposed to the apparatus during the vacation each showed decreases $(-3 \%,-43 \%$, and $-60 \%)$. No group differences attained acceptable levels of statistical reliability, so their data were pooled for summarization in Fig. 2. Matched-pairs randomization tests on the data of this figure reveal significant decreases following both the 15 -day and 7-day vacations $(p<.05)$. No regression was seen in any rat, either between vacations or following the second rest period, so it is difficult to say for sure whether the use of two vacations countered or prevented a return to baseline shock levels like that exhibited by several Ss in the previous experiment. It is clear that 30-min shock-free exposures to the apparatus on Vacation Days 4, 8, and 12 had no detrimental effect on the vacation-induced decrease in shock rate. Also clear is the finding that this decrease may be induced 


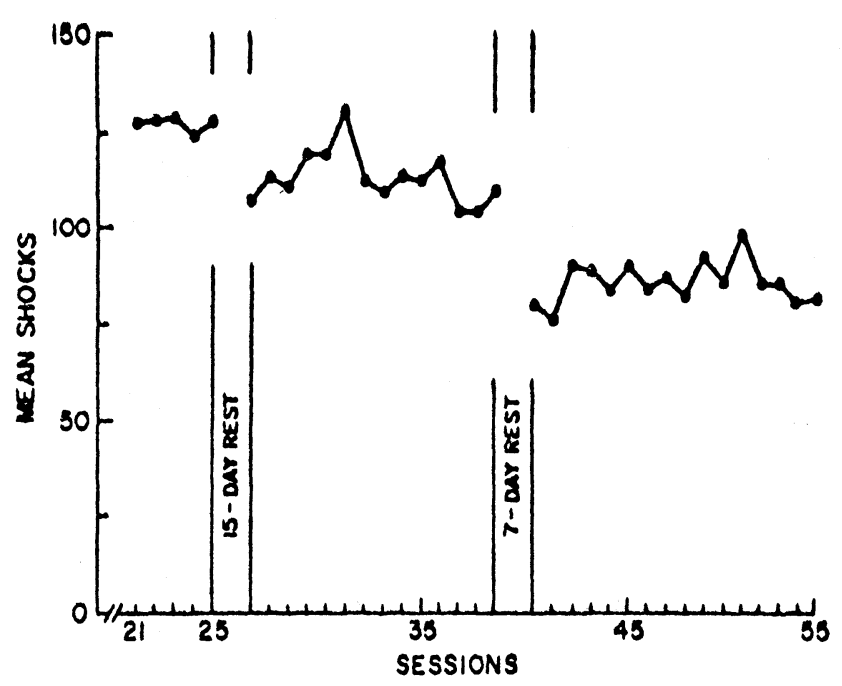

Fig. 2. Mean number of shocks per session $(N=6)$ during Experiment III.

more than once in the same $S$, despite changes in prevacation shock levels. Finally, at least under some circumstances, a vacation of only 7 days is sufficient to produce a significant decrease in the shock rates of nominally well-trained rats.

\section{GENERAL CONCLUSIONS}

In each of three experiments, stable, presumably asymptotic, shock avoidance was significantly enhanced by suspension of avoidance sessions for 1 to 4 weeks. Of $28 \mathrm{Ss}, 24$ showed lower shock rates upon resumption of daily avoidance testing, some improving by as much as $75 \%$. This improvement was not confined to any particular portion of the session, but extended throughout the entire 60- to 100 -min session. In many cases, this decrease in shock rate was accompanied by a rise in the overall number of leverpresses emitted in the postvacation sessions, but in many cases an increased number of moderate duration interresponse times $(4-18 \mathrm{sec})$ was more than offset by a substantial decrease in shock-elicited responses, resulting in no change, or even a decrease, in total number of presses.

This marked improvement was undiminished by variations in the experimental chamber and lever, duration of vacation, lesions of the amygdala, strain of rat, type or intensity of shock, duration of session, length or efficacy of prevacation training, and unshocked exposure to the apparatus during vacation. Several Ss showed some tendency to drift slowly back to prevacation shock rates, but for the majority, the improvement was permanent. We cannot satisfactorily explain the effect, but its practical utility in improving poor leverpress avoidance is obvious.

\section{REFERENCES}

Biederman, G. R., D'Amato, M. R., \& Keller, D. M. Facilitation of discriminated avoidance learning by dissociation of $\mathrm{CS}$ and manipulandum. Psychonomic Science, 1964, 1, 229-230.

Bolles, R. C. Species-specific defense reactions and avoidance learning. Psychological Review, 1970, 77, 32-48.

Cahoon, D. D., \& Crosby, R. M. A technique for the automatic shaping of escape and avoidance behavior in the operant conditioning chamber. Psychological Record, 1969, 19, 431-432.

Forgione, A. G. The elimination of interfering response patterns in leverpress avoidance situations. Journal of the Experimental Analy sis of Behavior, 1970, 13, 51-56.

Giulian, D., \& Schmaltz, L. W. Enhanced discriminated bar-press avoidance in the rat through appetitive preconditioning. Journal of Comparative \& Physiological Psychology, 1973, 83, 106-112.

Goddard, G. V. Functions of the amygdala. Journal of Comparative \& Physiological Psychology, 1964, 62, 89-109.

Silvestri, R., Rohrbaugh, M., \& Riccio, D. C. Conditions influencing the retention of learned fear in young rats. Developmental Psychology, 1970, 2, 389-395.

(Received for publication March 29, 1974.) 